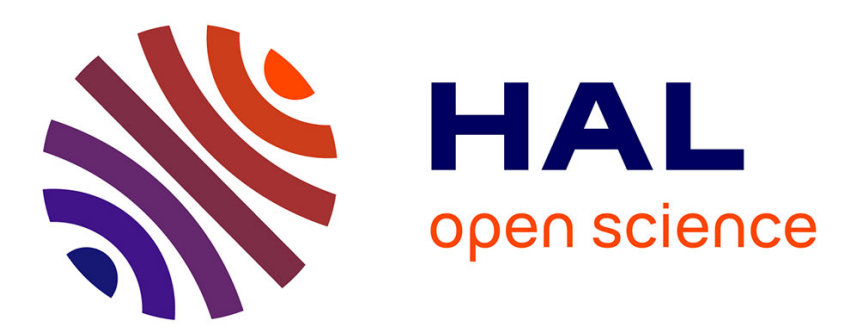

\title{
How fast do mobile organisms respond to stimuli? Response times from bacteria to elephants and whales
} Jean-Pierre Rospars, Nicole Meyer-Vernet

\section{To cite this version:}

Jean-Pierre Rospars, Nicole Meyer-Vernet. How fast do mobile organisms respond to stimuli? Response times from bacteria to elephants and whales. Physical Biology, 2021, 18 (2), 10.1088/14783975/abcd88 . hal-03171698

\section{HAL Id: hal-03171698 \\ https://hal.sorbonne-universite.fr/hal-03171698}

Submitted on 17 Mar 2021

HAL is a multi-disciplinary open access archive for the deposit and dissemination of scientific research documents, whether they are published or not. The documents may come from teaching and research institutions in France or abroad, or from public or private research centers.
L'archive ouverte pluridisciplinaire HAL, est destinée au dépôt et à la diffusion de documents scientifiques de niveau recherche, publiés ou non, émanant des établissements d'enseignement et de recherche français ou étrangers, des laboratoires publics ou privés. 


\section{HOW FAST DO MOBILE ORGANISMS RESPOND TO STIMULI?}

2 RESPONSE TIMES FROM BACTERIA TO ELEPHANTS AND WHALES

3

$4 \quad$ Jean-Pierre Rospars ${ }^{\mathrm{a}}$ and Nicole Meyer-Vernet ${ }^{\mathrm{b}}$

5

$6{ }^{a}$ Institute of Ecology and Environmental Sciences of Paris, INRA, route de Saint-Cyr, 78000

$7 \quad$ Versailles, France

$8 \quad{ }^{\mathrm{b}}$ LESIA, Observatoire de Paris, Université PSL, CNRS, Sorbonne Université, Université de

$9 \quad$ Paris, 5 place Jules Janssen, 92195 Meudon, France

10

11 Corresponding author: Jean-Pierre Rospars

12 Emails: Jean-Pierre.Rospars@,inrae.fr and Nicole.Meyer@obspm.fr

13

14 Manuscript length: 9800 words (title page, summary and statements not included)

15 Number of figures: 4.

16 Number of tables: 2.

17 Supplementary material: yes.

18

19 Keywords: response time, startle response, locomotion, biophysical modelling, biological scaling.

20

21

Published in Phys. Biol. 18 (2021) 026002

https://doi.org/10.1088/1478-3975/abcd88

Response times (revised version)

Phys. Biol.

Page 1 


\section{SUMMARY}

24 Quick responses to fast changes in the environment are crucial in animal behaviour and survival,

25 for example to seize prey, escape predators, or negotiate obstacles. Here, we study the 'simple

26 response time' that is the time elapsed between receptor stimulation and motor activation as

27 typically shown in escape responses, for mobile organisms of various taxa ranging from bacteria

28 to large vertebrates. We show that $95 \%$ of these simple response times lie within one order of

29 magnitude of the overall geometric mean of about $25 \mathrm{~ms}$, which is similar to that of a well-

30 studied sensory time scale, the inverse of the critical flicker fusion frequency in vision, also lying

31 within close bounds for all the organisms studied. We find that this time scale is a few times

32 smaller than the minimum time to move by one body length, which is known to lie also within a

33 relatively narrow range for all moving organisms. The remarkably small $10^{2}$-fold range of the

34 simple response time among so disparate life forms varying over $10^{20}$-fold in body mass suggests

35 that it is determined by basic physicochemical constraints, independently on the structure and

36 scale of the organism. We thus propose first-principle estimates of the simple response and

37 sensory time scales in terms of physical constants and a few basic biological properties common

38 to mobile organisms and constraining their responses. 
40

41

42 The concept of timescale is fundamental in science. An important timescale in biology is the

43 minimum response time of mobile organisms to a dynamic environment. When an animal

44 suddenly encounters a prominent event such as a prey, a predator or an obstacle, it must react

45 fast enough, albeit not faster than necessary, in order not to sacrifice accuracy or waste the

46 energy or space dedicated to its sensory systems (e.g. Attwell and Laughlin 2001). For a

47 response to be fast enough, the information that produced the response should not be outdated

48 (e.g. Spence 2009), which requires in particular that the response time does not exceed the

49 movement duration and that the animal position has not changed much. For animals moving with

50 legs, the response time is often compared to the stance or step duration (e.g. More et al. 2018);

51 however, for animals not equipped with legs, a more general time scale for comparison with the

52 minimum response time is the minimum time to move by one body length, that is the ratio of

53 body length to maximum speed.

54 The maximum speed of terrestrial and aquatic organisms has been found to be roughly

55 proportional to their body length, from bacteria to large vertebrates (Bonner 1965, McMahon and

56 Bonner 1983), contrary to the preferred speed which is subjected to different constraints (e.g.

57 Bejan and Marden 2006). These results, later confirmed with a large data set, imply that the time

58 to move by one body length at maximum speed lies in a narrow range around one tenth of

59 second within a factor of ten, for running and swimming organisms of mass varying by $10^{20}$-fold

60 in body mass. The ubiquity of this minimum locomotion time scale, holding for so different

61 organisms' structures and sizes, whereas characteristic biological timescales cover more than 12

62 orders of magnitude (e. g. Shamir et al. 2016), suggests that it is bounded by universal

63 constraints, and led Meyer-Vernet and Rospars $(2015,2016)$ to propose a tentative interpretation

Response times (revised version)

Phys. Biol.

Page 3 
64 based on the mass density of living organisms, the maximum specific tension exerted by

65 molecular motors and muscles (Rospars and Meyer-Vernet 2016) and the maximum mass

66 specific metabolic rate (Weibel and Hoppeler 2005, Glazier 2014, Makarieva et al. 2005), which

67 constrain the maximum speed and remain within close bounds for all moving organisms.

68 The question therefore arises of whether a similar result could hold for the minimum time to

69 react to stimuli. The scaling of sensorimotor delays with body mass in relation to movement

70 duration has been studied by More and Donelan (2018) for the stretch reflex in terrestrial

71 mammals, but there is no large-scale study of the minimum response time covering the entire

72 mass range of mobile species. We therefore collated data from the literature for the 'simple

73 response time', that is the time to detect the occurrence of a simple stimulus, as determined from

74 behavioural and electrophysiological measurements in various taxa from free-living cells to large

75 metazoans like sharks, turtles, and elephants, spanning 20 orders of magnitude in mass from

$76 \quad 10^{-16}$ to $3900 \mathrm{~kg}$.

77 An important constraint to fast response is set by sensory limitations that affect the ability to

78 track fast moving objects such as prey or mates. These limitations have been studied in the case

79 of vision, using the critical flicker fusion frequency (CFF), defined as the frequency at which a

80 flickering light is indistinguishable from a continuous light (e.g. D’Eath 1998). The scaling of

81 this property with body mass and metabolism has been studied by Healy et al. (2013) for

82 vertebrates; we collated the corresponding characteristic time (1/CFF) and extended the data to

83 compare it to the minimum response time.

84 Our aims are (i) to determine whether the minimum response time remains within close

85 bounds across the whole of mobile life despite the diversity of structures and mechanisms, (ii) to

86 compare it with the minimum sensory time-scale for vision (inverse of the critical flicker fusion

87 frequency) and to the minimum time to move by one body length, and (iii) to propose an

Response times (revised version) Phys. Biol. 
88 interpretation based on basic physicochemical and biological properties. Because the response 89 times of animals are expected to be hugely different from those of microorganisms, which are 90 subjected to very different constraints (e.g. Martens et al. 2015), we also investigate the 91 timescales separately for single cells and for metazoans.

92 The empirical data are studied and discussed in sections 2 to 4 . Section 5 proposes order-of93 magnitude interpretations based on fundamental physicochemical constants and basic properties 94 of life, with conclusions given in Section 6 .

96 2. MATERIAL AND METHODS

\subsection{Data Collection}

100 We define as "simple response time" $\left(T_{\mathrm{S}}\right)$ the time to detect the occurrence of a simple and 101 sudden stimulus. These $T \mathrm{~s}$ are delays from the time at which the stimulus reaches the organism to 102 either the onset of movement - measured by behavioural methods (for example with high-speed 103 cinematography), or to muscle activation - measured by electrophysiological methods with direct 104 recordings from muscles (electromyogram EMG). Since our study concerns minimum response 105 times, it does not include the "discrimination (or identification) and choice response times" (e.g. 106 Luce 1991). In these complex tasks, the subject, whether animal or human, is presented with one 107 of several stimuli and has to respond to only one of them (discrimination, e.g. Blough 1978) or to 108 perform different responses depending on the stimulus presented (choice between stimuli, e.g. 109 Abraham et al. 2004). Likewise, for microorganisms, we only considered the response delay after 110 a stimulus (e.g. Block et al. 1982), which only involves internal time scales of the organisms and 111 is shorter than the time based on the comparison of different measurements, which depends on 
112 ambient conditions (e.g. Mitchell 1991). Thus, our definition of simple response times $T_{\mathrm{S}}$ being

113 based on the simplicity of the task and the stimulus does not take into account the length,

114 variability or underlying sensorimotor mechanisms of the response delays (Roeder 1963, Koch

115 1999, Herberholz and Marquart 2012, Sillar et al. 2016, Roberts et al. 2019). It avoids the

116 operational difficulty to implement these multiple criteria and insures a better representativeness

117 of the sample.

118 We searched the Google Scholar database and extracted simple response times and other

119 relevant data (species names, stimuli, experimental conditions, etc.) published in refereed

120 journals. Our main objective being to investigate the interspecific variability, we kept all values

121 found for non-human species, but not for humans, for which we considered only a selection of

122 papers, either classical or illustrating the diversity of experimental paradigms. For a given species

123 and stimulus, we tabulated simple response times as the mean provided by the authors, or the

124 mean of the extremes when given as a range.

125 Our $T_{\mathrm{S}}$ sample (Table S1) includes 175 measurements on 81 species. Behavioural $(n=134)$

126 and electromyographic (EMG, $n=41)$ measurements (column $\mathrm{M}$ in Table S1) are not

127 significantly different (Fig. S2A and Table S10); thus, we pooled them together in subsequent

128 analyses. The data belong to two main classes: startle and non-startle. "A startle response is an

129 abrupt response, often of relatively short latency, to a sudden stimulus that we believe to be both

130 unexpected and alarming (i.e., of high valence)" (Bullock 1984), so that threats that develop

131 gradually are excluded. Startle responses form a homogeneous class gathering the majority of

132 measurements $(73 \%)$ and of species (68\%, multicellular only). They may result in a large

133 movement translating the whole body (escape, called fast-start in fishes, 86 measurements on 50

134 species) or in small movements (called sometimes 'eyelid, jaw, etc. reflex' in birds and

135 mammals, depending on the muscle triggered, 42 measurements in five species). Non-startle

$\begin{array}{lll}\text { Response times (revised version) } & \text { Phys. Biol. } & \text { Page } 6\end{array}$ 
136 responses (27\% of measurements on $32 \%$ of species) include taxes (in single cells only), reflex

137 control of locomotion, fast limb movements, predatory movements, and a few other fast

138 responses in multicellular organisms. Only six species were tested for more than one response 139 type.

140 For flicker fusion times $T_{\mathrm{F}}$, we used the CFF data from Healy et al. (2013) (34 vertebrate 141 species) and Inger et al. (2014) (31 invertebrate species and 41 vertebrate species not considered 142 by Healy et al. 2013), plus 25 other CFF measurements. Our sample $\left(T_{\mathrm{F}}=1 / \mathrm{CFF}\right.$, Table S2)

143 includes 130 measurements on 108 species. The values measured by behavioural $(n=26)$ and 144 electroretinographic (ERG, $n=103$, column M in Table S2) techniques are not significantly 145 different (Fig. S2C and Table S10); so, we pooled them together.

146 The minimum times to move by one body length $T_{\mathrm{L}}$ were collected and analysed previously 147 from the measured maximum speeds $V_{\max }$ of swimming and running organisms of length $L$ as $T_{\mathrm{L}}$ $148=L / V_{\max }$; this sample includes 458 measurements from 427 species (Table S3) and does not 149 include flying, whose maximum speed is not constrained by muscles (Meyer-Vernet and Rospars 150 2016).

151 For $T_{\mathrm{S}}$ and $T_{\mathrm{L}}$, we distinguished unicellular and multicellular organisms and spermatozoids $\left(T_{\mathrm{L}}\right.$ 152 only), as specified in column U of Tables S1 and S3. For the three timescales, column Cla of 153 Tables S1-S3 defines groups of phylogenetically related species; they belong to the same class in 154 multicellular organisms and to the same kingdom according to the WoRMS database (World 155 Register of Marine Species, http://www.marinespecies.org) in unicellular organisms (except 156 spermatozoids). Further details on Tables S1-S3 are given in Supplementary material.

157 Table S4 lists 14 mammalian species for which both minimum locomotor times $T_{\mathrm{L}}$ and 158 maximum mass specific metabolic rates (MSMR in $\mathrm{W} / \mathrm{kg}$ ) are known. 
162 We characterized body size by the mass $M$ for each species. Except for vertebrates with measured

163 CFFs from Healy et al. (2013) for which we used the mass provided by these authors, we

164 searched the original papers for mass, length or age. When given as a range, we took the mean.

165 We converted length in mass using either the length-mass relationship of the species when it is

166 known or a more generic relationship, for example $M_{\mathrm{kg}}=11.2 \mathrm{Lm}^{3.04}$ which applies to fusiform

167 fishes (Froese et al. 2014; see other relationships in Meyer-Vernet and Rospars 2016). When no

168 indication was provided in the papers, we searched the average mass (or length) of the species in

169 the scientific literature (for example, Bartholomew and Heinrich 1973; Byrne et al. 1988; Niven

170 and Scharlemann 2005, for insects; Falk-Petersen 1981, for shrimps) or in websites. We have not

171 considered in the analyses two $T_{\mathrm{F}}$ data for which the mass could not be found (lines 24 and 87 in

172 Table S2). Otherwise, all body masses and their references are given in Tables S1-S3.

\subsection{Temperature Effects}

175

176 In order to check the dependence of the time scales on temperature, we used (in the Discussion

177 section only) the Boltzmann-Arrhenius model from chemical reaction kinetics, which holds

178 approximately for metabolic and locomotor rates (e.g. Dell et al. 2011). This model yields

179 biological time scales inversely proportional to the Boltzmann factor, $\exp \left(-E / k_{\mathrm{B}} \theta\right)$, where $E$ is the

180 activation energy of the process studied (in joules), $k_{\mathrm{B}}$, the Boltzmann constant, and $\theta$, the

181 temperature (in kelvins). Thus, the corrected time scale $T_{0}$, at the reference temperature $\theta_{0}$, of

182 time $T$ measured at temperature $\theta$ is $T_{0}=T \exp \left(q E / k_{\mathrm{B}}\right)$, where $q=1 / \theta_{0}-1 / \theta$. For all timescales,

183 we chose $\theta_{0}=20^{\circ} \mathrm{C}$ as reference and $E=0.66 \mathrm{eV}$, the mean activation energy observed in a wide 
184 range of species and traits (Dell et al. 2001). In the special case of $T_{\mathrm{s}}$, we also applied a finer 185 standardization procedure distinguishing defence or movement away from a stimulus, like startle 186 responses, and consumption or movement toward a stimulus (almost all other responses), whose 187 mean activation energies are $E=0.4$ and $0.7 \mathrm{eV}$, respectively (Dell et al. 2001).

2.4. Statistical Analyses

Statistics were computed on either data $T$ or their $\log$-transform $\left(\log _{10} T\right)$. In the main text, but not

192 in Supplementary material, all data $\left(T\right.$ and $\left.\log _{10} T\right)$ were averaged per species, counting

193 separately sperm cells (in $T_{\mathrm{L}}$ data, Table S3) and late developmental stages (for Danio rerio and

194 Procambarus clarkii in $T_{\mathrm{S}}$ data, Table $\left.\mathrm{S} 1\right)$. The data in each category $\left(T_{\mathrm{S}}, T_{\mathrm{F}}\right.$ and $\left.T_{\mathrm{L}}\right)$ were

195 characterized by their medians and interquartile ranges IQR. Lognormal distributions were fitted

196 after determination of their parameters (mean $\mu$ and standard deviation $\sigma$ ) on log-transformed

197 data. However, for easier readability, $\mu$ in $\log$ units was converted in seconds in text and figures

198 (except in Supplementary material Tables S7-S10), as $\mu^{*}=10^{\mu}\left(\mu^{*}\right.$ is the geometric mean and

199 median of the lognormal distribution fitted to data $T$ ). Similarly, $\sigma$ was expressed as a

200 multiplicative standard deviation $\sigma^{*}=10^{\sigma}\left(\sigma^{*}\right.$, like $\sigma$, is dimensionless; it determines the

201 asymmetry of the distribution, and the interval $\left[\mu^{*} / \sigma^{*}, \mu^{*} \sigma^{*}\right]$ covers a probability of $68.3 \%$, see

202 Limpert et al. 2001). The overall interval of variation in each timescale was expressed as the

203 percentiles $2.5 \%$ and $97.5 \%$, which are less sensitive to outliers and sampling fluctuations than

204 the minimum and maximum; the ratio of these percentiles and its logarithm (denoted $\left.\delta T_{95}\right)$

205 estimate the multiplicative range including $95 \%$ of values. Statistical distributions were

206 compared with the Kolmogorov-Smirnov test. Least-square regressions of $\log _{10} T_{i}$ against

$207 \log _{10} M$ and least-rectangle regressions of $\log _{10} T_{\mathrm{L}}$ against $\log _{10} M S M R$ (Dagnelie 2011) were 
208 calculated and given as scaling equations $T_{i}=T_{0} M^{\alpha}$ in figures and their slope (also called scaling 209 exponent) $\alpha$ as $95 \%$ confidence intervals in the text. Tables S7-S10 provide details of ANOVA 210 and multiple comparisons of means using Tukey-Kramer adjustment method. We used the 211 significance level $5 \%$ in all tests. We performed all statistics with the Matlab Statistical Toolbox 212 (The Mathworks, Natick, USA).

213

214 3. EMPIRICAL RESULTS

215

216 3.1. Statistical Distributions of Timescales and Comparisons

217

218 Simple response times, $T_{\mathrm{S}}$, extend from $2.5 \mathrm{~ms}$ in the escape behaviour of the calanoid 219 copepod Undinula vulgaris to $485 \mathrm{~ms}$ in the acoustic response of the white whale Delphinapterus 220 leucas, with median $24 \mathrm{~ms}$ and IQR $43 \mathrm{~ms}$. The distribution is lognormal (Fig. S1A), with 221 geometric mean $\mu^{*}=26 \mathrm{~ms}$ and multiplicative standard deviation $\sigma^{*}=3.26$. Critical fusion times $222 T_{\mathrm{F}}$ range from $2.5 \mathrm{~ms}$ in the black fire beetle Melanophila acuminata to $250 \mathrm{~ms}$ in the crustacean 223 isopod Booralana tricarinata, with median $24 \mathrm{~ms}$ and IQR $27 \mathrm{~ms}$. The distribution is lognormal 224 (Fig. S1C) with $\mu^{*}=25 \mathrm{~ms}$ and $\sigma^{*}=2.14$. The times to move by one body length at maximum 225 speed $T_{\mathrm{L}}$ extend from $5 \mathrm{~ms}$ for a sea urchin to $2.8 \mathrm{~s}$ for a large spirochetes bacterium, with 226 median $71 \mathrm{~ms}$ and IQR $99 \mathrm{~ms}$ (Meyer-Vernet and Rospars 2016). The distribution is lognormal 227 with $\mu^{*}=78 \mathrm{~ms}$ and $\sigma^{*}=2.73$ (Fig. S1B). Since most of the variability in the data comes from 228 the diversity of species, stimuli and measurement methods, such lognormal distributions are 229 expected if these factors act in a multiplicative way.

230 Figure 1 compares as boxplots the (log-transformed) timescales $T_{\mathrm{F}}, T_{\mathrm{S}}$ and $T_{\mathrm{L}}$. Their relative 231 position is indicated by the medians (central red lines). ANOVA and multiple comparisons of 
232 means show that the sensory timescale $T_{\mathrm{F}}$ and the simple response time $T_{\mathrm{S}}$ are similar, whereas $T_{\mathrm{L}}$ 233 is significantly different and about three times longer (Table S7).

234

235

\subsection{Variation with Body Mass}

236

237 To study the dependence of simple response times on body mass $M$ for the whole data set 238 encompassing life's major domains, we plotted the pairs $\left(M, T_{\mathrm{S}}\right)$ in log-log plots for 81 species 239 (Fig. 2), including microorganisms in the mass range $10^{-16}$ (bacterium) to $5 \times 10^{-13} \mathrm{~kg}$ (green alga) 240 and multicellular organisms from $3 \times 10^{-9}$ (spider) to $3860 \mathrm{~kg}$ (elephant). Fig. 2A distinguishes the 241 taxonomic groups whereas Fig. 2B distinguishes the types of responses. Overall, the mass $M$ 242 varies by a factor of about $10^{20}$ whereas $95 \%$ of the $T_{\mathrm{S}}$ values lie between $4.7 \times 10^{-3}$ and $0.31 \mathrm{~s}$ 243 (Table 1, first line). Although very small, the slope of the regression line is significantly different 244 from zero (95\% confidence intervals $[-0.065,-0.010]$, Table 2$)$, but as shown in Table 1 , this 245 effect results from the larger simple response times in single cells $\left(\mu^{*}=129 \mathrm{~ms}\right)$ than in 246 multicellular organisms $\left(\mu^{*}=22 \mathrm{~ms}\right)$. Since this difference is significant (Table S8c, first line, $247 p<10^{-3}$ ), the two groups must be studied separately. The scaling exponents $\alpha$ of the power law 248 regressions in both groups are not significantly different from zero with $95 \%$ confidence 249 intervals $[-0.41,0.49]$ for single cells and $[-0.01,0.08]$ for multicellular organisms, whereas the 250 intercepts differ by more than one order of magnitude (Table 2 and Fig 2A).

251 Flicker fusion times $T_{\mathrm{F}}$ could only be measured in multicellular organisms. Therefore, the 252 body mass of the 106 species shown in Figure 3 only varies from $2 \times 10^{-6} \mathrm{~kg}$ (fruit fly) to $354 \mathrm{~kg}$ 253 (sea turtle), representing over eight orders of magnitude, whereas $95 \%$ of the $T_{\mathrm{F}}$ values lie 254 between $2.5 \times 10^{-3} \mathrm{~s}$ and $0.25 \mathrm{~s}$ (Table 1 ). No effect of body mass on $T_{\mathrm{F}}$ could be evidenced, since 255 the power law regression is $T_{\mathrm{F}}=0.026 M^{\alpha}$ (Fig 3), with $\alpha$ in the $95 \%$ CI $[-0.01,0.06]$ (Table 2). 
256 The times to move by one body length at maximum speed $T_{\mathrm{L}}$ (Meyer-Vernet and Rospars 257 2016, Fig. 4) concern 426 species including microorganisms from $10^{-16} \mathrm{~kg}$ (bacterium) to $2581.3 \times 10^{-8} \mathrm{~kg}$ (ciliate eukaryotic cell) and multicellular organisms from $10^{-9}$ (copepod) to $1.4 \times 10^{5}$ $259 \mathrm{~kg}$ (blue whale). So, $M$ varies by 21 orders of magnitude whereas $95 \%$ of the $T_{\mathrm{L}}$ values lie 260 between $21 \times 10^{-3}$ and $0.71 \mathrm{~s}$. The times $T_{\mathrm{L}}$ in single cells $\left(\mu^{*}=145 \mathrm{~ms}\right)$ are twice longer and 261 more variable than in multicellular organisms $\left(\mu^{*}=69 \mathrm{~ms}\right)$, this difference being significant 262 (Table S8b, second line, $p<10^{-8}$ ). In both groups $T_{\mathrm{L}}$ increases slightly with mass, since the $95 \%$ 263 CI of the slope of the regression line $\alpha$ is $[0.020,0.14]$ for single cells and $[0.028,0.060]$ for 264 multicellular organisms (Table 2). However, the trend of the multicellular group results from the 265 largest vertebrates since for species under $50 \mathrm{~kg}$ the slope of the regression law $\alpha$ is not 266 significantly different from zero $(95 \%$ CI is $[-0.030,0.11]$ (Table 2$)$.

267 Since the maximum metabolic rate of organisms affects their maximum speed (Meyer-Vernet 268 and Rospars 2016), we studied also the dependence of $T_{\mathrm{L}}$ on maximum specific metabolic rates 269 (MSMR) in 14 species of mammals for which both values were determined (Table S5). The slope 270 of the regression lines of MSMR against body mass (Fig. S6A) and of $T_{\mathrm{L}}$ against MSMR (Fig. 271 S6B) are not significantly different from 0 and -1 respectively, suggesting independence of 272 MSMR on mass and inverse dependence of $T_{\mathrm{L}}$ on MSMR.

273

274 4. DISCUSSION

275

276 4.1. Variability and Mass Dependency of Timescales

277

278 Over the whole mass range, the variabilities of the timescales expressed by the ranges including $27995 \%$ of the data $\left(\delta T_{95}\right.$, Table 1$)$, are so small compared to the mass ranges ( $\delta M$, Table 2$)$, that 
280 their ratios are always less than one in a million $\left(10^{\delta T 95} / 10^{\delta M}\right)$. Indeed, $95 \%$ of the simple 281 response times $T_{\mathrm{S}}$ (Fig. 2), of the visual resolution times $\left(T_{\mathrm{F}}=1 / \mathrm{CFF}\right.$, Fig. 3$)$ and of the minimum 282 locomotor times $T_{\mathrm{L}}$ (Fig. 4) lie within less than a factor of ten, five and six respectively of their 283 geometric mean, whereas the mass varies by 20,8 , and 21 orders of magnitude for $T_{\mathrm{S}}, T_{\mathrm{F}}$ and $T_{\mathrm{L}}$ 284 respectively. This is noteworthy, given the diversity of sensorimotor systems and the huge mass 285 range, and suggests that these times are strongly constrained by physics, as was previously 286 proposed for $T_{\mathrm{L}}$. The small variation of the visual resolution times is remarkable, given the 287 variation in spatiotemporal optical quality with eye size, which is correlated to body size (e.g. 288 Currea et al. 2018), and the large diversity of visual systems (e.g. Fernald 2000) and of strategies 289 of spatiotemporal summations. Although CFF is unrivaled to quantify the ability of an organism 290 to track a moving object, whether it is representative of other sensory systems is an open question 291 for further investigation. However, as suggested by a few reports (for example in olfaction, 292 Rumbo and Kaissling 1989, Lemon and Getz 1997, Smear et al. 2011, Jacob et al. 2017), 293 temporal resolution might reflect properties common to diverse neural networks rather than 294 specificities of the receptors (Butts et al. 2007, Panzeri et al. 2010) and, hence, be similar in the 295 visual and other sensory systems.

296 Most of the overall variability results from variations at smaller mass ranges. Within uni- and 297 multi-cellular organisms considered separately, the mass-scaling exponents are not significantly 298 different from zero or result from a small-scale trend ( $T_{\mathrm{L}}$ in large metazoans), so that the $T_{\mathrm{L}}$ 299 (small) mass dependency in single cells appears as an exception that will need further data to be 300 interpreted. For $T_{\mathrm{S}}$ and $T_{\mathrm{L}}$, differences between single cells and metazoans contribute to the 301 overall variability. The twice longer geometric mean of $T_{\mathrm{L}}$ in single cells (Table 1) is well 302 documented ( $n=70$ species) but the six times longer one of $T_{\mathrm{S}}(n=7)$ should be confirmed on a 303 larger sample. 
304 Although outside the scope of this paper, we examined narrower mass ranges, i.e. groups of 305 related species of the same class (or kingdom in microorganisms) including more than three 306 species (Fig. S3, S4, S5 and Table S6). For most groups, the mass scaling exponents are positive 307 with intercepts decreasing with mass, so that all the data still lie in a relatively narrow range, as 308 found previously for the mass specific metabolism (Makarieva et al. 2008, Hatton 2019) and its 309 maximum value (Makarieva et al. 2005). For simple response times $T_{\mathrm{S}}$, the only exponent that 310 reaches statistical significance is that of mammals (Fig. S3) where the trend explains $42 \%$ of the 311 variance and agrees with previous studies (section 4.3). Although not significant, the trend in 312 bacteria stands out owing to the proportion of variance it explains (81\%) and its steep slope $313(\alpha=0.66)$ which agrees with first-principle derivations (section 5). For the flicker fusion time, the 314 mass exponent of the small-scale regressions are not significantly different from zero. Finally, for 315 the minimum time to move by one body length, the positive mass scaling exponent of mammals 316 stems from large masses (the inflection point near $50 \mathrm{~kg}$ is apparent in Fig. 4), as noted and 317 interpreted by Meyer-Vernet and Rospars (2016); we shall return to this point in section 5.

\subsection{Possible Errors Resulting from Biological, Methodological and Experimental Factors}

321 Are our data and analyses adequate for supporting our conclusion that the simple response time

$322 T_{\mathrm{S}}$ lies within less than a factor of ten from the mean for organisms varying by more than 20 323 orders of magnitude in mass, as previously shown for the minimum time to move by one body 324 length $T_{\mathrm{L}}$ (Meyer-Vernet and Rospars 2016)? That a similar finding holds for $T_{\mathrm{F}}$ over the smaller $32510^{8}$-fold mass range for which this time could be measured? And that these time scales display 
326 small or no systematic variation with body mass in uni- and in multicellular organisms? Several 327 criticisms could be raised.

328 First, one could object that the diversity of organisms, of sensory and motor mechanisms, and 329 of experimental procedures hides any trend in the data. However, it is unlikely that the restriction 330 to more homogeneous data would reveal trends presently hidden because the smaller size of 331 samples would decrease the statistical significance. On the contrary, the diversity of species, 332 measurements and systems is indispensable to estimate reliably the variability and mean of the 333 timescales, independently of the specializations and limitations of taxa and systems. Our aim is to 334 transcend mass scalings holding within groups by considering large ranges of mass and 335 taxonomic groups.

336 Second, the evolution of different traits is correlated throughout a phylogenetic lineage so that 337 species values do not represent statistically independent data (Felsenstein 1985). This leads to 338 overestimation of degrees of freedom, which artificially narrows confidence intervals. Our major 339 finding that timescales lie within close bounds and that for unicellular (for $T \mathrm{~s}$ ) and multicellular 340 organisms (for all timescales) they do not significantly depend on mass would not be adversely 341 affected by any widening of confidence intervals (on the contrary for $T_{\mathrm{L}}$ in single cells) and is 342 therefore impervious to this criticism.

343 A third possible objection is that several experimental factors affecting the measurements have 344 not been considered explicitly. The electrical or behavioural measurement methods play a minor 345 role and correcting them would have practically no effect (Fig. S2 and Table S10 show that their 346 difference is not significant). However, the effect of temperature, which is an important 347 determinant of metabolism and behaviour, should be checked. We thus studied how correcting 348 the time scales of ectotherms to a standard temperature $\theta_{0}=20^{\circ} \mathrm{C}$ would change our results (see 349 Methods). First, the temperature being unknown in several measurements, we considered the 
350 worst-case scenario assuming that short time scales $\left(T<\mu^{*}\right)$ were measured at $10{ }^{\circ} \mathrm{C}$, and would

351 thus be still shorter if they had been measured at $\theta_{0}$, and that long time scales $\left(T \geq \mu^{*}\right)$ were

352 measured at $30^{\circ} \mathrm{C}$, these two temperatures being close to the extremes in our data (Fig. S7A). For

353 this preliminary test, we used the mean activation energy $E=0.66 \mathrm{eV}$ observed in a wide range

354 of species and traits (Dell et al. 2001), and studied how the percentage of timescales lying outside

355 the range $\left[\mu^{*} / 10, \mu^{*} \times 10\right]$ would be affected by temperature in this worst-case scenario. For all

356 timescales, this percentage is less than $3 \%$ without standardization (Table S11a) and less than

$35710 \%$ with standardization (Table $\mathrm{S} 11 \mathrm{~b}$ ), except for $T_{\mathrm{S}}$ where it is $5 \%$ and $22 \%$ respectively.

358 Next, noting the greater sensitivity of $T \mathrm{~s}$, we applied a finer standardization procedure to this

359 timescale, for which the temperature is known in $72 \%$ of our data for ectothermic species, based

360 on the different mean activation energies of movements away from and toward a stimulus (see

361 Methods). This procedure leads to no significant change neither in the distribution of $T_{\mathrm{S}}$ values

362 (Fig. S7B) nor in the number of species beyond the limits (it remains the same, i. e. four, Fig.

363 S7). This indicates that our results in mean, variability and overall trend are robust with respect to 364 temperature.

366 4.3. Comparison with Previous Work

368 Several studies across a wide range of mass and life forms have found organisms' properties to

369 lie in a relatively narrow range, without mass scaling across groups, despite the size scaling

370 observed within groups. This is the case for the mass-specific metabolic rate (Makarieva et al.

371 2008, Hatton et al. 2019), its maximum value per unit of active mass (Makarieva et al. 2005), the

372 cross-section-specific forces exerted by muscles and molecular motors (Marden and Allen 2002, 
373 Marden 2005, Rospars and Meyer-Vernet 2016), and the minimum time to move by one body 374 length $T_{\mathrm{L}}=L / V_{\max }$ (McMahon and Bonner 1983, Meyer-Vernet and Rospars 2015, 2016).

375 However, for the simple response time $T_{\mathrm{S}}$ and the critical flicker fusion time $T_{\mathrm{F}}$, previous 376 studies concern only relatively small mass ranges and we have included these data. The mass 377 scaling of sensorimotor delays has been studied by More and Donelan (2018) in the particular 378 case of the stretch reflex - a monosynaptic reflex that governs the fastest neural response to 379 peripheral stimuli in terrestrial mammals, with a determination of the different components and a 380 comparison with stance and stride durations. In our $T_{\mathrm{S}}$ sample, we have used the sum of these 381 components except the force generation delay (time between force onset and peak), in coherence 382 with the rest of our data, for which the response is measured by the onset of force production or 383 the onset of movement (which can begin before the production of peak force). These data points 384 lie within the range of our general data set $T_{\mathrm{S}}$ for multicellular organisms, where the nerve 385 conduction delay is expected to be mainly responsible for the increase of $T_{\mathrm{S}}$ shown in figure 2 at 386 large mass. Indeed, the increase in nerve conduction speed due to increase in fibre diameter and 387 to myelination is too moderate to compensate for the increase in distance of conduction, because 388 of the trade-off between responsiveness and compactness (Castelfranco and Hartline 2016), 389 resolution (More et al. 2013), and energy cost (Perge et al. 2012). Let us compare the nerve 390 conduction delay estimated by More and Donelan (2018) $T_{\text {cond }}=5.3 M^{0.3} \mathrm{~ms}$ to the geometric 391 mean $\left(T_{\mathrm{S}}=22 \mathrm{~ms}\right)$ that we find for multicellular species (Table 1). This yields

$392 T_{\mathrm{cond}} / T_{\mathrm{S}}=0.24 M^{0.3}$, which shows that the conduction delay becomes important only for large $M$, 393 although even for the largest mammal studied (the elephant), $T_{\mathrm{s}}$ is only four times larger than its 394 average value. 


\section{QUANTITATIVE INTERPRETATIONS FROM FIRST PRINCIPLES}

397

398 The variation of the simple response time, as well as the other time scales studied here, by less

399 than a factor of ten around their mean for organisms so diverse in structure and size suggests that

400 it may be determined by basic constraints set by the universal properties of living matter. We will

401 thus derive first-principle estimates, trying to capture the essential processes at play, whereas

402 neglecting specific details that should be considered in scaling studies over narrow ranges of

403 mass and taxa. Such simple analytic calculations are expected to yield only order-of-magnitude

404 results, that is to within a 10-fold or so accuracy, similar to the variability of the time scales in

405 our data, in the line of the so-called "Fermi problems" or of Weisskopf's physics courses

406 (Weisskopf 1975, 1989).

407

408 5.1. Simple Response Time

409

410 Consider first the simple response time $T$ s of microorganisms. It includes the transmission delay

411 from the sensor(s) receiving external stimuli to the motor apparatus producing the response by

412 regulating the swimming behaviour. A basic process is the transport of a signalling molecule

413 through the cytoplasm (e.g. Bitbol and Wingreen 2015) via diffusion (e.g., Purcell 1977,

414 Dusenberry 2009). In water, of viscosity $\eta \simeq 10^{-3} \mathrm{~kg} \mathrm{~m}^{-1} \mathrm{~s}^{-1}$, a sphere of diameter $d$ at

415 temperature $\theta$ has a diffusion coefficient $D=k_{\mathrm{B}} \theta /(3 \pi \eta d)$, where $k_{\mathrm{B}}$ is Boltzmann constant.

416 Signalling molecules are small proteins of typical size $d \simeq 3 \mathrm{~nm}$, like the key signalling protein

417 CheY (Bren and Eisenbach 2000), yielding a diffusion coefficient in water $D \simeq 150 \mu \mathrm{m}^{2} / \mathrm{s}$.

418 Assuming that the crowding of the cytoplasm decreases $D$ by one order of magnitude (e.g. Dill et 
419 al. 2011, Mika and Poolman 2011) and that the sensor-to-motor distance equals the organism's

420 length $L$, we find the three-dimensional diffusion time $L^{2} / 6 D$

$421 \tau \tau_{\text {dif }} \simeq 10 L_{\mu \mathrm{m}^{2}} \mathrm{~ms}$.

422 This timescale is the minimum response time $T_{\mathrm{S}}$ of a microorganism of size $L$ if information is

423 transmitted through the cytoplasm by diffusion of signalling proteins, which is the most basic

424 process. With $L \propto M^{1 / 3}$, this would yield a mass variation $T \mathrm{~S} \propto M^{2 / 3}$, as observed for bacteria (see

425 the leftmost regression line in Figure S3 with slope $\alpha=0.66$, as given in Table S5). The median

426 mass of a bacterium of length $L$ being $M \simeq(3.3 L)^{3}$ (Meyer-Vernet and Rospars 2016), the length

427 of a bacterium of mass $10^{-15} \mathrm{~kg}\left(\mu_{\mathrm{M}}^{*}\right.$, Table S6) is $L \simeq 3 \mu \mathrm{m}$. We deduce from Eq. (1) $T_{\mathrm{S}}=90$

$428 \mathrm{~ms}$, which agrees to better than a factor of two with the empirical value for bacteria $\left(\mu^{*}=144 \mathrm{~ms}\right.$

429 in Table S5) and is close to the response time given by their regression line $(T \mathrm{~s}=100 \mathrm{~ms}$ for $430 \quad M=10^{-15} \mathrm{~kg}$, Table S6).

431 Consider now multicellular organisms. For most of them, the responses are mediated by 432 conduction of information via electric pulses propagating through neurons, whose membrane 433 regulates the permeation of ions via an insulating lipid bilayer and proteins. The proteins act as 434 active ion channels and pumps and the lipid bilayer acts as a capacitance that enables charges to 435 accumulate and produce a potential across it. Biological membranes are also involved in sense 436 organs, via the concentration gradients they enable which produce active transport, whereas ion 437 channels play an essential role in signal transduction (Martinac and Cox 2016). The role of ions 438 to alter charge and thus protein conformation is essential in signal transduction in both uni- and 439 multicellular organisms (Clapham 2007). For example, paramecia use $\mathrm{Ca}^{2+}$ ions and show 440 dynamic changes in the electrical properties of their membrane in response to stimuli, as do 
441 neurons, and the structures of their receptors are similar to those of vertebrates (e.g. Maegawa 442 2017).

443 A tentative first principle estimate of $T$ s can be obtained from the inverse of the number of 444 action potentials sent along an axon per second, since this is the shortest possible time to send a 445 bit of information along an axon. Let us first evaluate the cost of generating an action potential $U$ 446 per surface $S$ of membrane, of width $a$ and dielectric constant $\varepsilon$ m, so that the capacitance is

$447 \quad C \simeq \varepsilon_{0} \varepsilon_{\mathrm{m}} S / a$,

448 where $\varepsilon_{0}$ is vacuum permittivity. With the electric charge across the membrane $C U$, of energy

$449 C U^{2}$, the cost of an action potential is obtained from (2) as $\varepsilon_{0} \varepsilon \mathrm{m} S U^{2} / a$, which agrees with values

450 in the literature (Aiello 2000). Using two biological properties common to living matter: the mass

451 density $\rho \simeq 10^{3} \mathrm{~kg} / \mathrm{m}^{3}$ and the maximum metabolic rate per unit mass of active tissue

$452 b_{\mathrm{M}} \simeq 2 \times 10^{3} \mathrm{~W} / \mathrm{kg}$ (Makarieva et al. 2005), the maximum power available to this surface $S$ of

453 membrane of mass $\rho a S$ is

$454 \quad b_{\mathrm{M}} \rho a S$

455 Dividing this maximum power by the cost of an action potential estimated above and using the 456 energy corresponding to one monovalent ion crossing the membrane $e U \simeq W_{0}$, where

$457 e=1.6 \times 10^{-19} \mathrm{C}$ is the electron charge and $W_{0}$ is the energy released by one ATP molecule, we 458 deduce the maximum number of action potentials per unit time, whose inverse yields

$459 \quad T_{\mathrm{S}} \simeq \varepsilon_{0} \varepsilon_{\mathrm{m}} W_{0}^{2} /\left(\rho b_{\mathrm{M}} e^{2} a^{2}\right)$

460 Substituting the typical dielectric constant of lipids $\varepsilon_{\mathrm{m}} \simeq 2$, a membrane width $a \simeq 6 \mathrm{~nm}-$ similar 461 to the typical protein size (e.g. Erickson 2009), the above value of $b \mathrm{M}$, and the first-principles 462 relation (Meyer-Vernet and Rospars 2016)

$463 \quad W_{0} \simeq e^{2} /(4 \pi \varepsilon 0 a)$ 
464 we obtain $T_{\mathrm{S}} \simeq 14 \mathrm{~ms}$, close to the empirical mean simple response time $T_{\mathrm{S}}$ of metazoans (22 $465 \mathrm{~ms})$.

\section{5.2. Flicker Fusion Time}

468

469 Let us now estimate the timescale $T_{\mathrm{F}}$, assuming that it is limited by the membrane time constant

$470 \tau_{\mathrm{m}}$. For a surface $S$ of membrane of width $a$ and resistivity $r_{\mathrm{m}}$, the electrical resistance is

$471 R=r_{\mathrm{m}} a / S$ and the capacitance is given by (2), so that the time constant $\tau_{\mathrm{m}}=R C$ is given by

$472 \tau_{\mathrm{m}}=r_{\mathrm{m}} \varepsilon_{0} \varepsilon_{\mathrm{m}}$.

473 To estimate a basic value for the resistivity $r_{\mathrm{m}}$, independent on the details of the system, we

474 consider again energy constraints. In an electrical circuit of resistance $R$, submitted to the 475 potential difference $U$, the power is $U^{2} / R$. Using the maximum power available (3), we deduce

476 the resistance $R \simeq U^{2} /\left(b_{\mathrm{M}} \rho\right.$ a $\left.S\right)$, whence the resistivity $r_{\mathrm{m}} \simeq U^{2} /\left(\rho b_{\mathrm{M}} a^{2}\right)$. Using again the order

477 of magnitude $U \simeq W_{0} / e$, we deduce $\tau_{\mathrm{m}}$, which yields the flicker fusion time $T_{\mathrm{F}} \simeq \tau_{\mathrm{m}}$ (reflecting the

478 ability of the membrane to resolve a time-varying signal)

$479 \quad T_{\mathrm{F}} \simeq \varepsilon_{0} \varepsilon_{\mathrm{m}} W_{0}^{2} /\left(\rho b_{\mathrm{M}} e^{2} a^{2}\right) \simeq T_{\mathrm{S}} \simeq 14 \mathrm{~ms}$

480 close to the empirical value of $T_{\mathrm{F}}(25 \mathrm{~ms})$, and in agreement with our empirical result $T_{\mathrm{F}} \simeq T_{\mathrm{s}}$.

481 The absence of significant increase of $T_{\mathrm{F}}$ for the largest masses (Fig. 3), contrary to what is

482 observed for $T_{\mathrm{S}}$ (Fig. 2) suggests that the signal conduction time and hence the organism length $L$ 483 plays a minor role in $T_{\mathrm{F}}$, contrary to $T_{\mathrm{s}}$.

\subsection{Minimum Locomotion Time}

486 
487 An order of magnitude estimate of the minimum time to move by one body length $T_{\mathrm{L}}=L / V_{\max }$

488 was derived by Meyer-Vernet and Rospars (2016) from the invariance over the whole domain of

489 life of the force per cross-sectional area exerted by molecular motors and muscles $\left(f \simeq W_{0} / a^{3} \simeq\right.$

$4902 \times 10^{5} \mathrm{~N} / \mathrm{m}^{2}$, Rospars and Meyer-Vernet 2016), and the two basic quantities considered above,

491 mass density $\rho$ and mass-specific (per unit mass of active tissue) metabolic rate at maximum

492 activity $b_{\mathrm{M}}$. The maximum speed was estimated as $V_{\max } \simeq L \rho b_{\mathrm{M}} / f$ for swimming and running

493 organisms (including microorganisms) of length $L$ satisfying $L \lesssim(f / \rho)^{3 / 2} / b_{\mathrm{M}} \simeq 1.4 \mathrm{~m}-$

494 corresponding roughly to $M \simeq 50 \mathrm{~kg}$ (Meyer-Vernet and Rospars 2016). This yields $T_{\mathrm{L}} \simeq L / V_{\max }$,

495 the minimum time to move by $L$

$496 \quad T_{\mathrm{L}} \simeq f /\left(\rho b_{\mathrm{M}}\right) \simeq W_{0} /\left(\rho b_{\mathrm{M}} a^{3}\right) \simeq 100 \mathrm{~ms}$

497 for $M \lesssim 50 \mathrm{~kg}$, which agrees to better than a factor of two with the empirical value (59 ms,

498 geometric mean of $T_{\mathrm{L}}$ for all organisms of mass $M<50 \mathrm{~kg}$, Table 1). The increase in $T_{\mathrm{L}}$ observed

499 for larger organisms (Fig. 4) has been interpreted by dynamic constraints, yielding

$500 \quad T_{\mathrm{L}} \simeq L(\rho / f)^{1 / 2}$

501 (Meyer-Vernet and Rospars 2016), in agreement with the known maximum speed of about 15

502 m/s (e.g. McMahon and Bonner 1983, Garland, 1983, Iriarte-Diaz 2002).

503 It is interesting to note that our estimates of the minimum times for response (4), for vision

504 (7), and for moving by one body length (8) all yield timescales proportional to the inverse of the

505 maximum mass-specific metabolic rate (per unit of active mass). This suggests that, since the

506 metabolic rate varies with mass within groups of related species, these time scales may depend

507 not only on body mass within groups of related species but also on metabolic rates. This is shown

508 for $T_{\mathrm{L}}$ in mammals (Fig. S6B), which is inversely proportional to the maximum mass-specific

Response times (revised version) Phys. Biol.

Page 22 
509 metabolic rate, as expected from (8) if the proportion of active tissue in the body mass does not 510 vary in the range considered in the regression.

511 Finally, it is noteworthy that Eqs. (4), (5) and (8) yield $T_{\mathrm{L}} / T_{\mathrm{S}} \simeq 4 \pi / \varepsilon \mathrm{m} \simeq 6$ in order of 512 magnitude, to be compared to the empirical ratio $T_{\mathrm{L}} / T_{\mathrm{S}}=78 / 26=3$, suggesting that fast reacting 513 species are also fast moving.

515 6. CONCLUSIONS

517 We have shown that across the whole of mobile life, from bacteria to large vertebrates, the simple 518 response time $T_{\mathrm{S}}$ lies in a relatively narrow range, with $95 \%$ of species reacting in a time that 519 differs by less than one order of magnitude from the mean, in striking contrast to the 20 orders of 520 magnitude difference in body mass. The simple response time does not display significant scaling 521 with body mass across groups in unicellular organisms nor in multicellular ones, although it is 522 almost six times larger in the former life form. The absence of large-scale trend does not preclude 523 - and is indeed compatible with various scalings valid in narrower ranges of size and taxa, as is 524 known for the specific metabolic rate. However, within narrow ranges, the detailed characteristics 525 of the organisms must be considered and it is only on larger scales that these variations can be 526 transcended.

527 This simple response time $T_{\mathrm{s}}$ is close to a well-studied sensory timescale (the inverse of the 528 critical flicker fusion frequency for vision) $T_{\mathrm{F}}$, and is a few times smaller than the minimum time 529 to move by one body length $T_{\mathrm{L}}$, with all time scales lying in a relatively narrow range. Since this 530 narrow range suggests that these time scales may be strongly constrained by physics and basic 531 properties of life, independently of the structure or mass of the organism, we have performed 
532 tentative simple estimates of $T_{\mathrm{S}}$ and $T_{\mathrm{F}}$ based on fundamental physicochemical constants and 533 basic properties common to motile organisms.

534 It is fair to note that the agreement between these simple estimates of minimum time scales 535 (for sensing, for reacting and for moving) and the measurements is only indicative of the 536 dominant constraints in play (e.g. Phillips and Milo 2009), since several mechanisms may be 537 operating in parallel. For example, one tenth of second is in the middle of the range of protein 538 folding time scales, which however spans six orders of magnitude (e.g. Lane and Pande 2013) 539 and close to the maximal turn-over rate of the most abundant enzyme in the biosphere (e.g. 540 Flamholz et al. 2019). The relation $T_{\mathrm{S}} \simeq T_{\mathrm{F}}<T_{\mathrm{L}}$ found from the data (Fig. 1) and tentatively 541 interpreted from first-principles, is reminiscent of symmorphosis (Weibel et al. 1991) and 542 expected to be favoured by evolution since it is indicative of an optimum state. Indeed, if $T_{\mathrm{S}}<T_{\mathrm{F}}$ 543 the sensory resolution would be in excess over motor control whereas if $T_{\mathrm{S}}>T_{\mathrm{F}}$ the response 544 would be limited by sensory performance, so that in both cases, at least one component of the 545 nervous system would be out of tune and wasting energy or space (Laughlin 2001). Likewise, the 546 evolution is expected to favour organisms for which the sensory and response organs act fast 547 enough with respect to their moving performances. It is noteworthy that since the first-principle 548 estimate (8) of $T_{\mathrm{L}}$ holds for both uni- and multi-cellular organisms (Meyer-Vernet and Rospars 549 2016), the estimate (1) of the minimal response time $T$ s yields a maximal length $L$ of a few 550 micrometres in order to ensure $T_{\mathrm{S}} \leq T_{\mathrm{L}}$ when the response is mediated by diffusion, as observed 551 for bacteria

552 These preliminary results encourage further research on the response times of mobile 553 organisms and their fundamental bases. They might also possibly be used to infer properties of 554 extinct species since the reconstructed speed (e.g. Hutchinson and Garcia 2002) and size (e.g. 
555 Hutchinson et al. 2011) of the giant dinosaur Tyrannosaurus rex yield a time to move by one 556 body length $T_{\mathrm{L}} \simeq 1 \mathrm{~s}$ for a mass $M \simeq 10^{4} \mathrm{~kg}$, which is close to the value expected from (9) and 557 would put Tyrannosaurus rex in the middle of the data of extent animals of this size in figure 4. 558 
559 Ethical Statement

560 The present article is based on a meta-analysis. No live animals were used.

561

562 Data Accessibility

563 The datasets supporting the article are included in the Supplementary Material.

564

565 Competing Interests

566 We have no competing interests.

567

568 Author's Contributions

569 J.-P.R. and N.M.-V. each made significant and substantial contributions to this study in terms of

570 the conception, design, data collection and interpretation of results, as well as preparing the

571 manuscript. J.-P.R. contributed primarily to the statistical analyses and N.M.-V. to the physical

572 analyses.

573 


\section{REFERENCES}

575

576 Abraham, N. M., Spors, H., Carleton, A., Margrie, T. W., Kuner, T. and Schaefer, A. T. (2004).

577 Maintaining accuracy at the expense of speed: stimulus similarity defines odor

578 discrimination time in mice. Neuron, 44 (5), 865-876

579 Agutter, P. S. and Wheatley, D. N. (2004) Metabolic scaling: consensus or controversy? Theor.

$580 \quad$ Biol. Med. Model. 1 (1), 13

581 Aiello, G. L. and Bach-Y-Rita, P. (2000) The cost of an action potential. J. Neuroscience

$582 \quad$ Methods 103, 145-149

583 Attwell, D. and Laughlin, S. B. (2001) An energy budget for signaling in the grey matter of the 584 brain. J. Cerebral Blood Flow Metabol. 21 (10), 1133-1145

585 Bartholomew, G. A. and Heinrich, B. (1973) A field study of flight temperatures in moths in 586 relation to body weight and wing loading. J. Exp. Biol. 58, 123-135

587 Bejan, A. and Marden, J. H. (2006) Unifying constructal theory for scale effects in running, $588 \quad$ swimming and flying. J. Exp. Biol. 209 (2), 238-248

589 Bitbol, A. F. and Wingreen, N. S. (2015) Fundamental constraints on the abundances of 590 chemotaxis proteins. Biophys. J. 108 (5), 1293-1305

591 Block, S. M., Segall, J. E. and Berg, H. C. (1982) Impulse responses in bacterial chemotaxis. $592 \quad$ Cell, $31(1), 215-226$

593 Blough, D. S. (1978) Reaction times of pigeons on a wavelength discrimination task. J. Exp. 594 Anal. Behav., 30 (2), 163-167

595 Bonner, J T (1965) Size and Cycle: An Essay on the Structure of Biology (Princeton N J: 596 Princeton University Press) 
597 Bren, A. and Eisenbach, M. (2000) How signals are heard during bacterial chemotaxis: protein598 protein interactions in sensory signal propagation. J. Bacteriol. 182 (24), 6865-6873

599 Bullock, T. H. (1984) Comparative neuroethology of startle, rapid escape, and giant fiber600 mediated responses. In Neural Mechanisms of Startle Behavior (ed. R.C. Eaton), pp. 1-13. 601 Boston: Springer Science and Business Media

602 Butts, D. A., Weng, C., Jin, J., Yeh, C. I., Lesica, N. A., Alonso, J. M. and Stanley, G. B. (2007) 603 Temporal precision in the neural code and the timescales of natural vision. Nature 449, 9260495

605 Byrne, D.N., Buchmann, S.L. and Spangler, H.G. (1988) Relationship between wing loading, 606 wingbeat frequency and body mass in homopterous insects. J. Exp. Biol. 135, 9-23.

607 Castelfranco, A. M. and Hartline, D. K. (2016) Evolution of rapid nerve conduction. Brain Res. $608 \quad 1641,11-33$.

609 Clapham, D.E. (2007) Calcium signaling. Cell, 131 (6), 1047-1058

610 Currea, J. P., Smith, J. L. and Theobald, J. C. (2018) Small fruit flies sacrifice temporal acuity to 611 maintain contrast sensitivity. Vision Res. 149, 1-8

612 Dagnelie, P. (2011) Statistique théorique et appliquée. Tome 2. Inférence statistique à une et à 613 deux dimensions. Bruxelles, De Boeck

614 D'Eath, R. B. (1998) Can video images imitate real stimuli in animal behaviour experiments?. 615 Biol. Rev. 73 (3), 267-292.

616 Dell, A. I., Pawar, S., and Savage, V. M. (2001) Systematic variation in the temperature 617 dependence of physiological and ecological traits. Proc. Natl. Acad. Sci. 108 (26), 10591$618 \quad 10596$.

619 Dill, K. A., Ghosh, K. and Schmidt, D. (2011) Physical limits of cells and proteomes Proc. Nat. $620 \quad$ Acad. Sci. USA 108 17876-17882

Response times (revised version) Phys. Biol. 
621 Dusenberry, D. B. (2009) Living at Micro Scale. The Unexpected Physics of Being Small.

622 Cambridge, MA: Harvard University Press

623 Erickson, H. P. (2009) Size and shape of protein molecules at the nanometer level determined by 624 sedimentation, gel filtration, and electron microscopy, in Biological procedures Online ed 625 Shulin Li vol 11, 1

626 Falk-Petersen, S. (1981) Ecological investigations on the zooplankton community of Balsfjorden, 627 Northern Norway: seasonal changes in body weight and the main biochemical composition 628 of Thysanoessa inermis (Krøyer), T. raschii (M. Sars), and Meganyctiphanes norvegica (M. 629 Sars) in relation to environmental factors. J. Exp. Mar. Biol. Ecol. 49, 103-120

630 Felsenstein, J. (1985) Phylogenies and the comparative method. The American Naturalist, 125(1), $631 \quad 1-15$

632 Fernald, R. D. (2000) Evolution of eyes. Curr. Opin. Neurobiol. 10 (4), 444-450

633 Flamholz, A. I., Prywes, N., Moran, U., Davidi, D., Bar-On, Y. M., Oltrogge, L. M., Alves, R., 634 Savage, D. and Milo, R. (2019) Revisiting trade-offs between Rubisco kinetic parameters $635 \quad$ Biochemistry 58, 3365-76

636 Froese, R., Thorson, J. T. and Reyes, R. B. (2014) A Bayesian approach for estimating length637 weight relationships in fishes. J. Applied Ichthyol. 30, 78-85

638 Garland, T. Jr. (1983) The relation between maximal running speed and body mass in terrestrial 639 mammals. J. Zool., 199, 157-70

640 Glazier, D. (2014) Metabolic scaling in complex living systems. Systems, 2 (4), 451-540

641 Hatton, I. A., Dobson, A. P., Storch, D., Galbraith, E. D. and Loreau, M. (2019) Linking scaling 642 laws across eukaryotes. Proc. Natl. Acad. Sci. DOI: 10.1073/pnas.19004921161900492116 643 Healy, K., McNally, L., Ruxton, G. D., Cooper, N. and Jackson, A. L. (2013) Metabolic rate and 644 body size are linked with perception of temporal information. Animal Behav. 86 (4), 685-696 
645 Herberholz, J. and Marquart, G. D. (2012) Decision making and behavioral choice during predator 646 avoidance. Front. Neurosci. 6, 125

647 Hutchinson, J. R. and Garcia, M. (2002) Tyrannosaurus was not a fast runner. Nature 415, 1018$648 \quad 1022$

649 Hutchinson, J. R., Bates, K. T., Molnar, J., Allen, V. and Makovicky, P. J. (2011) A

650 computational analysis of limb and body dimensions in Tyrannosaurus rex with implications 651 for locomotion, ontogeny, and growth. PLoS One, 6, e26037

652 Inger, R., Bennie, J., Davies, T. and Gaston, K. (2014) Potential biological and ecological effects 653 of flickering artificial light. PLoS One 9, e98631

654 Iriarte-Diaz, J. (2002) Differential scaling of locomotor performance in small and large terrestrial 655 mammals. J. Exp. Biol. 205, 2897-2908

656 Jacob, V., Monsempès, C., Rospars, J.-P., Masson, J.-B. and Lucas, P. (2017) Olfactory coding in 657 the turbulent realm. PLoS Comput. Biol. 13 (12): e1005870

658 Koch, M. (1999) The neurobiology of startle. Progress in neurobiology, 59 (2), 107-128

659 Lane, T. J. and Pande V. S. (2013) Inferring the rate-length law of protein folding. PLoS One $660 \quad$ e78606

661 Laughlin, S. B. (2001) Energy as a constraint on the coding and processing of sensory 662 information. Curr. Opinion in Neurobiol., 11, 475e480

663 Lemon, W. and Getz, W. (1997) Temporal resolution of general odor pulses by olfactory sensory 664 neurons in American cockroaches. J. Exp. Biol., 200 (12), 1809-1819

665 Limpert, E., Stahel, W. A. and Abbt, M. (2001) Log-normal distributions across the sciences: $666 \quad$ keys and clues. BioSci. 51 (5), 341-352

667 Luce, R. D. (1991) Response Times. New York: Oxford University Press.

Response times (revised version) Phys. Biol. 
668 Makarieva, A. M., Gorshkov, V. G. and Li, B. L. (2005) Energetics of the smallest: do bacteria 669 breathe at the same rate as whales?. Proc. R. Soc. B: Biol. Sci. 272 (1577), 2219-2224

670 Makarieva, A. M., Gorshkov, V. G., Li, B. L., Chown, S. L., Reich, P. B. and Gavrilov, V. M.

671 (2008) Mean mass-specific metabolic rates are strikingly similar across life's major domains:

672 Evidence for life's metabolic optimum. Proc. Natl. Acad. Sci. 105, 16994-16999

673 Maegawa, S. (2017) Molecular characteristics of neuron-like functions in single-cell organisms, 674 In Shigeno et al. eds Brain Evolution by Design: from Neutral Origin to Cognitive $675 \quad$ Architecture, Springer

676 Marden, J. H. and Allen, L R. (2002) Molecules, muscles, and machines: universal performance 677 characteristics of motors. Proc. Natl. Acad. Sci. USA 99, 4161-4166

678 Marden, J. H. (2005) Review: Scaling of maximum net force output by motors used for 679 locomotion. J. Exp. Biol. 208, 1653-64

680 McMahon, T. A. and Bonner, J. T. (1983) On Size and Life (New York: Scientific American $681 \quad$ Library)

682 Mika, J. T. and Poolman, B. (2011) Macromolecule diffusion and confinement in prokaryotic 683 cells. Current Opinion in Biotechnology 22, 117-126

684 Martens, E.A., Wadhwa, N., Jacobsen, N. S., Lindemann, C., Andersen, K. H. and Visser, A. 685 (2015) Size structures sensory hierarchy in ocean life. Proc. R. Soc. B, 282, 20151346

686 Martinac, B. and Cox, C. D. (2016) Mechanosensory transduction: Focus on ion channels. 687 Comprehensive Biophysics, Elsevier

688 Medina, J. M., Wong, W., Diaz, J. A. and Colonius, H. (2015) Advances in modern mental 689 chronometry. Front. Human Neurosci. 9, 256

690 Meyer-Vernet, N. and Rospars, J. P. (2015) How fast do living organisms move: Maximum 691 speeds from bacteria to elephants and whales. Am. J. Phys. 83 (8), 719-722

Response times (revised version) Phys. Biol. 
692 Meyer-Vernet, N. and Rospars, J. P. (2016) Maximum relative speeds of living organisms: Why 693 do bacteria perform as fast as ostriches? Phys. Biol. 13 (6), 066006

694 Mitchell, J. G. (1991).The influence of cell size on marine bacterial motility and energetics. 695 Microbial Ecology, 22 (1), 227-238

696 More, H. L. and Donelan, J. M. (2018) Scaling of sensorimotor delays in terrestrial mammals. 697 Proc. R. Soc. B: Biol. Sci. 285 (1885), 20180613

698 More, H. L., Hutchinson, J. R., Collins, D. F., Weber, D. J., Aung, S. K. H. and Donelan, J. M. 699 (2010) Scaling of sensorimotor control in terrestrial mammals. Proc. R. Soc. B 277, 3563 $700 \quad 3568$

701 Niven, J. E. and Scharlemann, J. P. W. (2005) Does metabolic rate at rest and during flight scale 702 with body mass in insects? Biol. Lett. 1, 346-349

703 Panzeri, S., Brunel, N., Logothetis, N. K. and Kayser, C. (2010) Sensory neural codes using 704 multiplexed temporal scales. Trends Neurosci. 33 (3), 111-120

705 Perge, J. A., Niven, J. E., Mugnaini, E., Balasubramanian, V. and Sterling, P. (2012) Why do 706 axons differ in caliber? J. Neurosci. 32 (2), 626-638

707 Phillips, R. and Milo, R. (2009) A feeling for the numbers in biology Proc. Natl. Acad. Sci. 106, $708 \quad 21465-21471$

709 Purcell, E. M. (1977) Life at low Reynolds number. Am. J. Phys. 45 (1), 3-11

710 Roberts, A., Borisyuk, R., Buhl, E., Ferrario, A., Koutsikou, S., Li, W. C. and Soffe, S. R. (2019)

711 The decision to move: response times, neuronal circuits and sensory memory in a simple 712 vertebrate. Proc. R. Soc. B, 286 (1899), 20190297

713 Roeder, K. D. (1963) Nerve Cells and Insect Behavior. Cambridge, USA: Harvard University $714 \quad$ Press, $188 \mathrm{pp}$. 
715 Rospars, J. P. and Meyer-Vernet, N. (2016) Force per cross-sectional area from molecules to 716 muscles: a general property of biological motors. R. Soc. Open Sci. 3 (7), 160313

717 Rumbo, E. R. and Kaissling, K. E. (1989) Temporal resolution of odour pulses by three types of 718 pheromone receptor cells in Antheraea polyphemus. J. Comp. Physiol. A, 165 (3), 281-291

719 Sillar, K. T., Picton, L. D. and Heitler, W. J. (2016) The Neuroethology of Predation and Escape. $720 \quad$ John Wiley \& Sons

721 Shamir, M., Bar-On, Y., Phillips, R. and Milo, R. (2016) Snapshot: timescales in cell biology. $722 \quad$ Cell 164, 1302-1303

723 Smear, M., Shusterman, R., O’connor, R., Bozza, T. and Rinberg, D. (2011) Perception of sniff 724 phase in mouse olfaction. Nature, 479 (7373), 397-400

725 Spence, A. J. (2009) Scaling in biology. Current Biology 19, R57-R61

726 Weibel, E. R., Taylor, C. R. and Hoppeler, H. (1991) The concept of symmorphosis: A testable 727 hypothesis of structure-function relationship Proc. Natl. Acad. Sci. USA 88, 10357-10361

728 Weibel, E. R. and Hoppeler, H. (2005) Exercise-induced maximal metabolic rate scales with 729 muscle aerobic capacity. J. Exp. Biol. 208 (9), 1635-1644

730 Weisskopf, V. F. (1975) Of atoms, mountains, and stars: a study in qualitative physics. Science, $731 \quad 187(4177), 605-612$

732 Weisskopf, V. F. (1989) The Privilege of Being a Physicist (W. H. Freeman, New York, 1989) 733 
734 TABLE 1. Summary statistics of timescales (in ms) for unicellular, multicellular and all species 735

$736 \quad$ Timescale $\quad n \quad \min \max Q_{2.5} Q_{97.5} \quad r_{95} \delta T_{95}$ med IQR $\mu^{*} s^{*}$ out95 out $_{10}$

737

739

$T_{S}$ all

$81 \quad 2.5 \quad 485$

$4.7 \quad 311$

66.1 .82

$\begin{array}{lllll}7 & 18.0 & 350 & 18.0 & 350\end{array}$

$\begin{array}{llllllll}19 & 1.29 & 200 & 195 & 129 & 3.17 & 0 & 0\end{array}$

740

$T_{S}$ unicell

$74 \quad 2.5 \quad 485$

$4.7 \quad 238$

$\begin{array}{lllllllll}51 & 1.71 & 23 & 35 & 22 & 2.93 & 4 & 3\end{array}$

741

$T_{S}$ multic $<50 \mathrm{~kg}$

$\begin{array}{lll}68 & 2.5 & 240\end{array}$

$4.6 \quad 148$

$\begin{array}{llllllll}32 & 1.51 & 18 & 28 & 19 & 2.64 & 4 & 1\end{array}$

742

743

$T_{\mathrm{F}}$ all multic 106

2.5250

$4.2 \quad 100$

$\begin{array}{llllllll}24 & 1.37 & 24 & 27 & 25 & 2.14 & 5 & 1\end{array}$

744

745

$$
T_{\mathrm{L}} \text { all }
$$

427

$5.32778 \quad 20.9 \quad 706$

341.53

7199

978

$2.73 \quad 22 \quad 11$

746

$T_{\mathrm{L}}$ unicell

70

$5.32778 \quad 11.92778$

$\begin{array}{llllllll}234 & 2.37 & 123 & 213 & 145 & 3.86 & 2 & 9\end{array}$

$\begin{array}{lllllllllllllll}747 & T_{\mathrm{I}} \text { multicell } & 357 & 12.5 & 2525 & 22.3 & 567 & 25 & 1.41 & 61 & 82 & 69 & 2.40 & 18 & 3\end{array}$

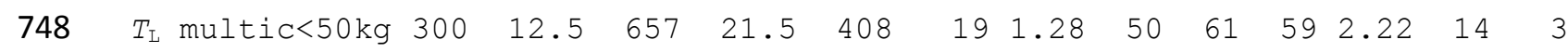

749

750 Rows: $T_{\mathrm{S}}$, simple response time; $T_{\mathrm{F}}$, flicker fusion time; $T_{\mathrm{L}}$, minimum time to move by one body

751 length.

752 Columns: $n$, number of species; minimum; maximum; $Q_{2.5}$, percentile $2.5 \%$; $Q_{97.5}$, percentile

$753 \quad 97.5 \%$; r95, ratio $Q_{97.5} / Q_{2.5}$ including $95 \%$ values; $\delta T_{95}=\log _{10}\left(r_{25}\right)$; med, median; IQR,

754 interquartile range; $\mu^{*}$, geometric mean $(\mathrm{ms}) ; s^{*}$, multiplicative standard deviation; out 95 , number

755 of values outside $\left[Q_{2.5}, Q_{97.5}\right]$; out 10 , number of values outside $\left[\mu^{*} / 10, \mu^{*} \times 10\right]$.

756

Response times (revised version)

Phys. Biol.

Page 34 
757 TABLE 2. Dependence of timescales on body mass for unicellular, multicellular and all species 758

$n \quad \log _{10} T_{0} \quad \alpha \quad \mathrm{IC}_{1} \quad \mathrm{IC}_{2} \quad \mu_{\mathrm{M}^{*}} \quad \delta M \quad r_{\alpha} \quad \delta T_{\alpha} \quad r^{2} \quad P$ Sig

760

761

$T_{\mathrm{S}}$ all

$\begin{array}{llllllllllllll}81 & -1.69 & -0.033 & -0.06 & -0.01 & -3.10 & 19.59 & 0.2 & -0.64 & 7 & 0.02 & 1\end{array}$

$762 T_{S}$ unicell

$7-0.35$

$0.038-0.41$

$0.49-14.17$

$\begin{array}{llllll}3.70 & 1.4 & 0.14 & 1 & 0.83 & 0\end{array}$

763

$T_{\mathrm{S}}$ multicell

$74-1.58$

$0.036-0.01$

$\begin{array}{llll}0.08 & -2.05 & 12.11 & 2.7\end{array}$

$\begin{array}{llll}0.44 & 3 & 0.12 \quad 0\end{array}$

764

$T_{S}$ multic $<50 \mathrm{~kg}$

$68-1.77-0.024-0.08$

$0.03-2.45$

$9.890 .6 \quad-0.24 \quad 10.36 \quad 0$

765

766

$T_{\mathrm{F}}$ all multic $106-1.57$

$0.023-0.01$

$0.06 \quad-1.93$

$\begin{array}{llllll}8.25 & 1.6 & 0.19 & 2 & 0.19 & 0\end{array}$

767

$768 \quad T_{\mathrm{L}}$ all

769

$T_{\mathrm{L}}$ unicell

$427-1.13-0.010-0.02-0.00$

$\begin{array}{lllllll}-2.86 & 21.05 & 0.6 & -0.20 & 1 & 0.03 & 1\end{array}$

770

$T_{\mathrm{L}}$ multicel

$\begin{array}{lll}70 & 0.10 \quad 0.078\end{array}$

0.02

$0.14-12.01$

$\begin{array}{llllll}8.01 & 4.2 & 0.63 & 10 & 0.01 & 1\end{array}$

771

TL multic $<50 \mathrm{~kg}$

$357-1.11$

0.044

0.03

$\begin{array}{lllllllll}0.06 & -1.06 & 14.15 & 4.2 & 0.62 & 7 & 0.00 & 1\end{array}$

772

773 Rows: same as in Table 1.

774 Columns: $n$, number of species; $\log _{10} T_{0}$, intercept of least square regression $\operatorname{line}, \log _{10} T=\log _{10} T_{0}$

$775+\alpha \log _{10} M ; \alpha$, allometric coefficient; $\left[\mathrm{IC}_{1}, \mathrm{IC}_{2}\right], 95 \%$ confidence intervals of slope $\alpha ; \mu \mathrm{M}^{*}$, mean

$776 \log _{10} M ; \delta M$, mass range of the category, $\delta M=\log _{10}\left(M_{\max } / M_{\min }\right)$, with $M_{\max }$ and $M_{\min }$ masses of 777 heaviest and lightest species in the category; $r_{\alpha}$, fitted ratio $T_{\max } / T_{\min }$ with $T_{\max }=T_{0}\left(M_{\max }\right)^{\alpha}$ and $778 T_{\min }=T_{0}\left(M_{\min }\right)^{\alpha} ; \delta T_{\alpha}=\log _{10} r_{\alpha} ; r^{2}$, coefficient of determination (percent); $P, \mathrm{p}$-value of test of 779 slope $\alpha=0$; Sig, slope $\alpha$ of regression line significantly different from zero (1) or not (0). 780 


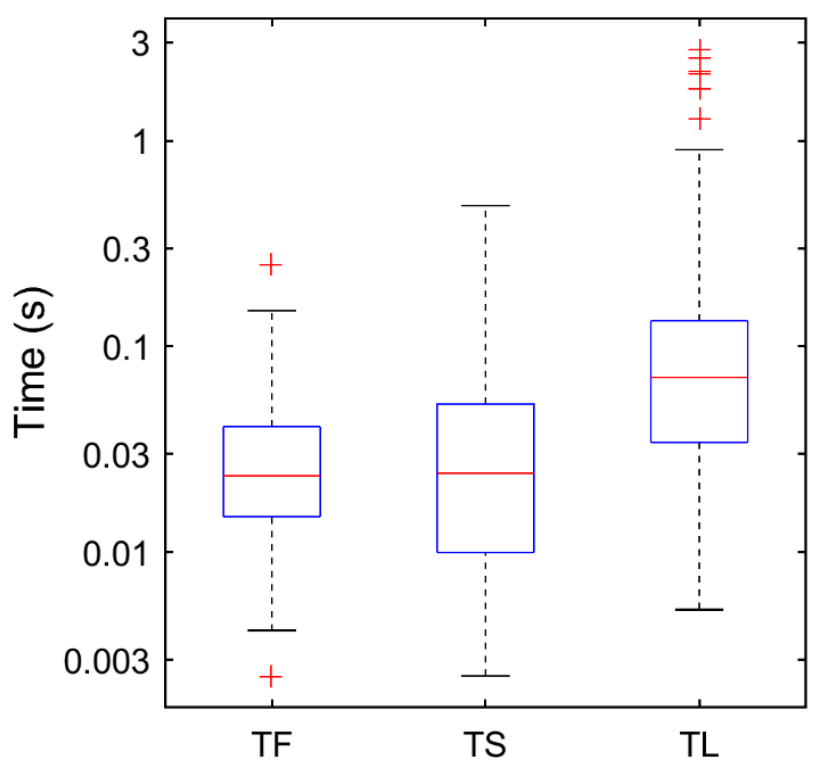

781

782 Figure 1. Boxplots of log-transformed flicker fusion times $T_{\mathrm{F}}$, simple response times $T_{\mathrm{S}}$, and

783 times to move by one body length at maximum speed $T_{\mathrm{L}}$. The boxes extend from the lower

784 quartile to the upper quartile values with the medians (red line) in between. The whiskers extend

785 to the most extreme data values within 1.5 $\times$ IQR. Outliers (red crosses) are values beyond the end

786 of the upper whiskers. ANOVA and multiple comparisons of means (Supplementary material,

787 Table S7): $T_{\mathrm{F}}=T_{\mathrm{S}} \neq T_{\mathrm{L}}$.

788 

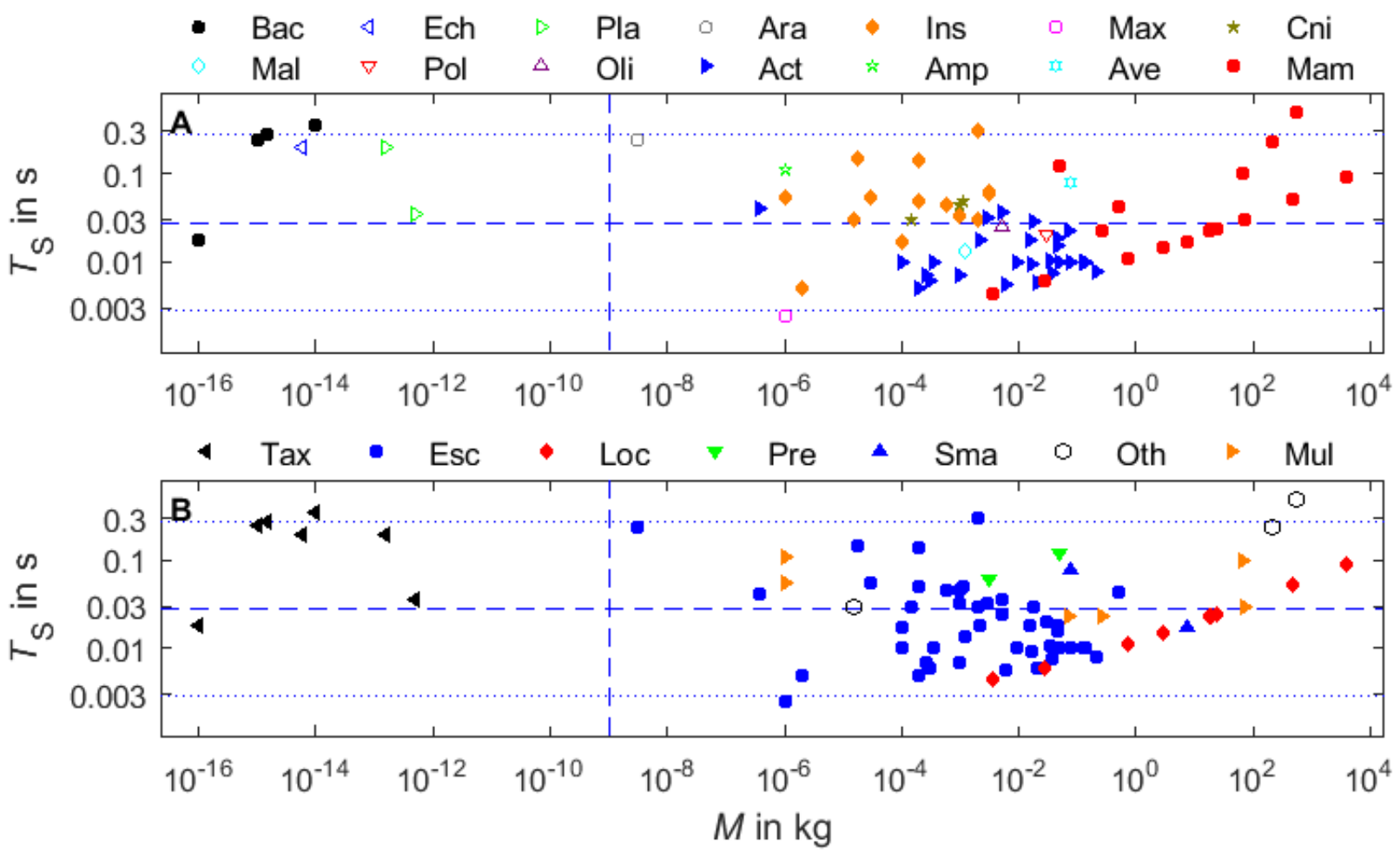

790 Figure 2. Simple response times $T_{\mathrm{S}}$ versus cell or body mass $M(n=81)$. For clarity, the scale on 791 the $\mathrm{y}$-axis is 1.5 times larger than on the $\mathrm{x}$-axis .

792 A. Taxonomic groups. Groups with three species or less shown as empty symbols, other groups 793 as filled symbols. Bacteria (Bac, $n=4)$, Echinodermata (Ech, 1, sperm), Planta (Pla, 2), 794 Arachnida (Ara, 1), Insecta (Ins, 16), Hexanauplia (Hex, 1; copepods), Cnidaria (Cni, 3), 795 Malacostraca (Mal, 2; crustaceans), Polychaeta (Pol, 1; bristle annelids), Oligochaeta (Oli, 1; 796 earthworms), Actinopterygii (Act, 28; cartilaginous fishes), Amphibia (Amp, 1), Aves (Ave, 1; 797 birds), Mammalia (Mam, 18). The horizontal dashed line is the geometric mean $\mu^{*}(26 \mathrm{~ms})$ with 798 values larger and smaller by one order of magnitude dotted. Vertical dashed line separates 799 unicellular from multicellular organisms. Intermediate-scale regression laws for, from left to 800 right, single cells (solid black line), multicellular organisms above $50 \mathrm{~kg}$ excluded (dashed black 801 line) and included (solid black line). Slopes not significantly different from zero.

802 B. Types of response. Species tested for a single type of response shown in filled symbols: cell 803 chemotaxis and phototaxis (Tax, $n=7$ ), startle with escape (Esc, 46), sensory control of 804 locomotion (Loc, 11), predatory movement (Pre, 6), small movement in startle of birds and 805 mammals (Sma, 2), other behaviour (Oth, 3; see Table S1). Species tested for two or more types 806 of response (empty symbol, Mul, 6). Dashed and dotted horizontal lines as in A. 


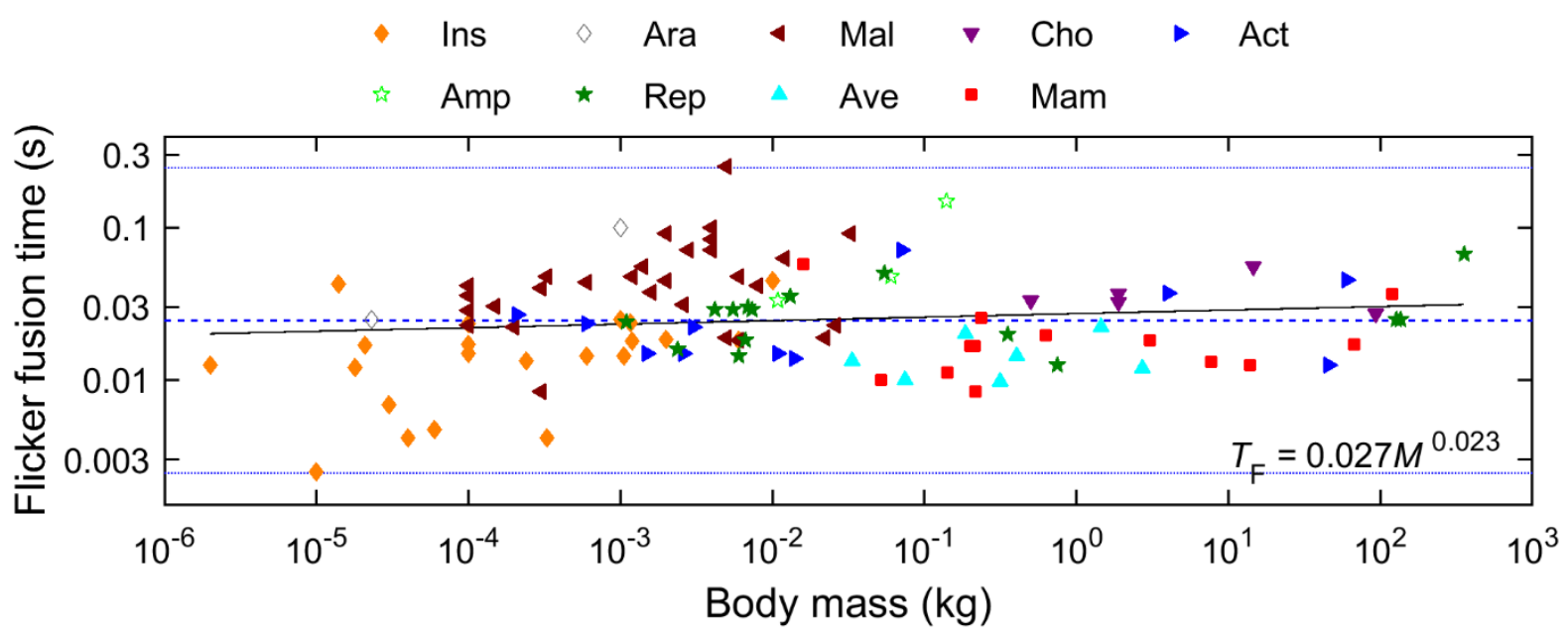

807

808 Figure 3. Flicker fusion times $T_{\mathrm{F}}$ versus body mass $M(n=106)$ according to taxonomic groups,

809 shown as colour of empty and filled symbols as in Fig. 2. Arachnida (Ara, $n=2)$, Insecta (Ins,

810 21), Malacostraca (Mal, 29; crustaceans), Cho (Chondrichthyes, 5; cartilaginous fishes),

811 Actinopterygii (Act, 11; ray-finned fishes), Amphibia (Amp, 3), Reptilia (Rep, 15), Aves (Ave, 7;

812 birds), Mammalia (Mam, 13). The horizontal dashed line is the geometric mean $\mu^{*}(25 \mathrm{~ms})$ with

813 values larger and smaller by one order of magnitude dotted. Scaling regression law in inset. Slope

814 not significantly different from zero. 


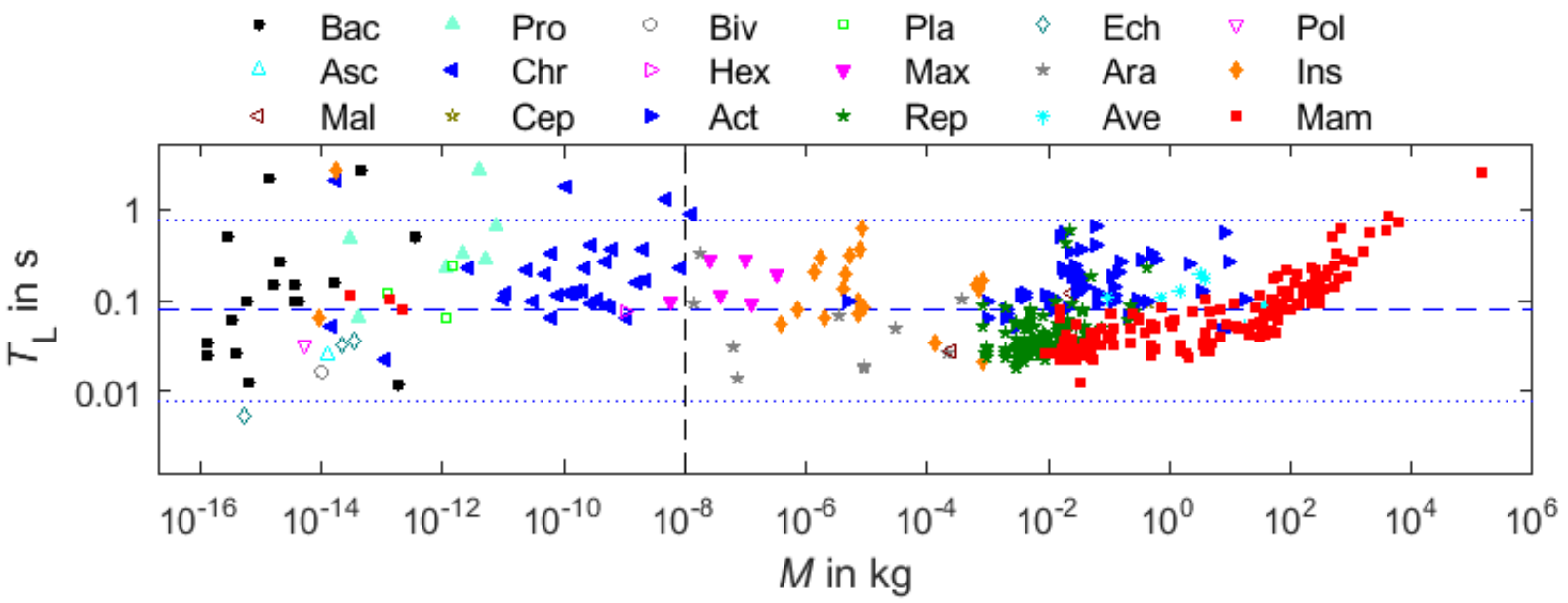

816

817 Figure 4. Times to move by one body length at maximum speed $T_{\mathrm{L}}$ versus cell or body mass

$818(n=426)$ according to taxonomic groups. For clarity, the scale on the y-axis is 1.5 times larger 819 than on the X-axis. Groups with three species or less shown as empty symbols, other groups as 820 filled symbols. Bacteria (Bac, $n=17$ ), Protozoa (Pro, 7; flagellates), Bivalvia (Biv, 1, sperm), 821 Planta (Pla, 3), Echinodermata (Ech, 3, sperm), Polychaeta (Pol, 1, sperm; bristle annelids), 822 Ascidiacea (Asc, 1, sperm; sea squirts), Chromista (Chr, 32; ciliates), Hexanauplia (Hex, 6; 823 copepods), Arachnida (Ara, 10), Insecta (Ins, 20; 2 sperm), Malacostraca (Mal, 3; crustaceans), 824 Cephalopoda (Cep, 1), Actinopterygii (Act, 55; cartilaginous fishes), Reptilia (Rep, 96), Aves 825 (Ave, 9; birds), Mammalia (Mam, 161; 3 sperm). The horizontal dashed line is the geometric 826 mean $\mu^{*}(78 \mathrm{~ms})$ with values larger and smaller by one order of magnitude dotted. Vertical 827 dashed line approximately separates unicellular and multicellular organisms. Intermediate-scale 828 regression laws in inset as in Fig. 2. Slopes significantly different from zero, except for 829 multicellular organisms under $50 \mathrm{~kg}$. 